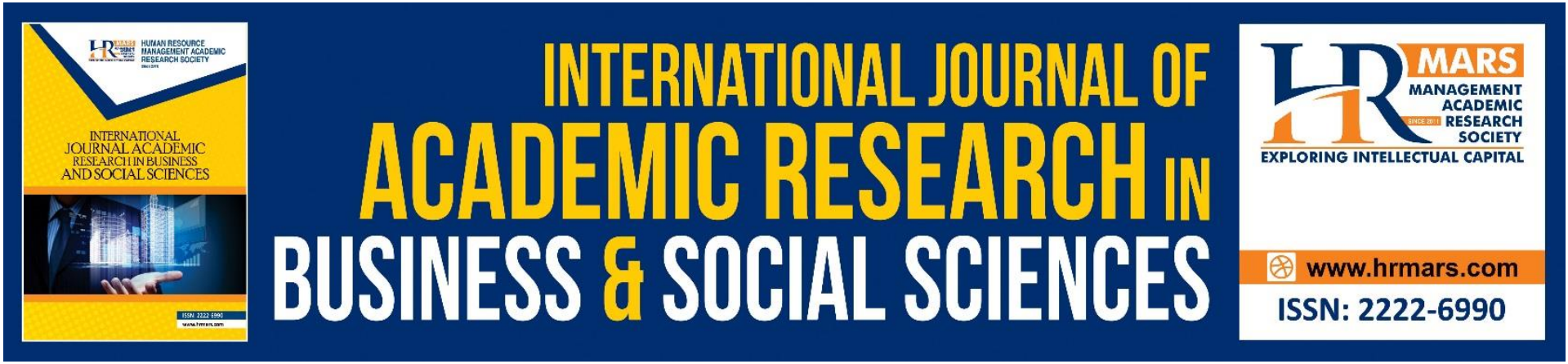

\title{
Depression and Suicidal Ideation among University Students
}

Friskilaconttselvinia Anthony Aning, Cyndra Robert Budull, Noreriani Sabturani, Theresa Ahing \& Nur Khairunisa Abu Talip

To Link this Article: http://dx.doi.org/10.6007/IJARBSS/v11-i12/11465

DOI:10.6007/IJARBSS/v11-i12/11465

Received: 06 October 2021, Revised: 08 November 2021, Accepted: 23 November 2021

Published Online: 07 December 2021

In-Text Citation: (Aning et al., 2021)

To Cite this Article: Aning, F. A., Budull, C. R., Sabturani, N., Ahing, T., \& Talip, N. K. A. (2021). Depression and Suicidal Ideation among University Students. International Journal of Academic Research in Business and Social Sciences, 11(12), 1995-2004.

\section{Copyright: @ 2021 The Author(s)}

Published by Human Resource Management Academic Research Society (www.hrmars.com)

This article is published under the Creative Commons Attribution (CC BY 4.0) license. Anyone may reproduce, distribute, translate and create derivative works of this article (for both commercial and non0-commercial purposes), subject to full attribution to the original publication and authors. The full terms of this license may be seen at: http://creativecommons.org/licences/by/4.0/legalcode

\section{Vol. 11, No. 12, 2021, Pg. 1995- 2004}

Full Terms \& Conditions of access and use can be found at http://hrmars.com/index.php/pages/detail/publication-ethics 


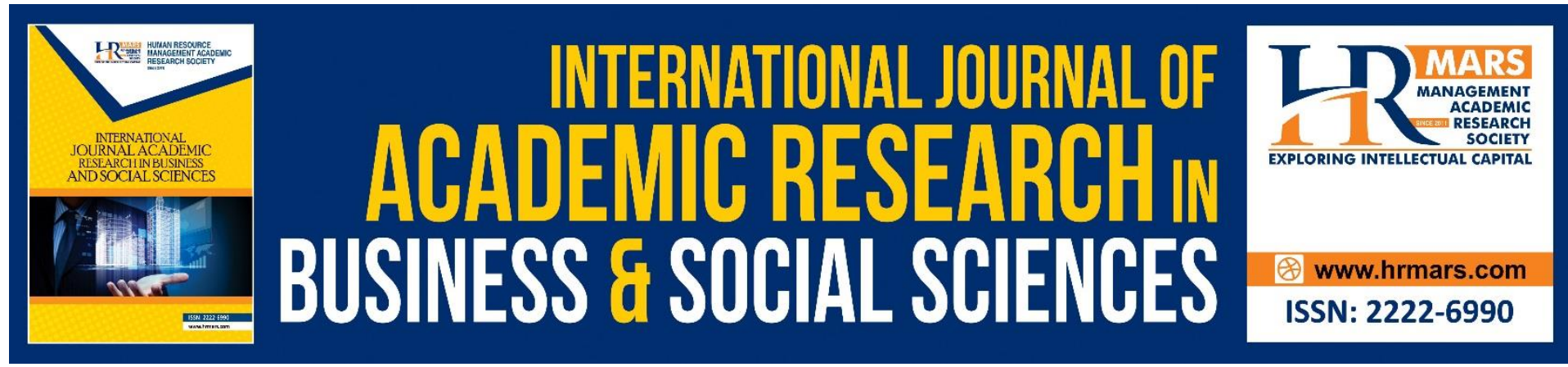

\title{
Depression and Suicidal Ideation among University Students
}

\author{
Friskilaconttselvinia Anthony Aning, Cyndra Robert Budull, \\ Noreriani Sabturani, Theresa Ahing \& Nur Khairunisa Abu Talip \\ Faculty of Sports Science and Recreation, Universiti Teknologi MARA, Samarahan Branch, \\ Sarawak, Malaysia \\ Email: friskila.anthony@gmail.com,cyndra1424@uitm.edu.my, \\ noreriani4070@uitm.edu.my, theresaahing@uitm.edu.my,nurkhairunisa331@uitm.edu.my
}

\begin{abstract}
Purpose of the study: Depression is a common mental disorder which had become a powerful trigger of suicidal ideation. The aim is to identify the difference and relationship of depression and suicidal ideation among university students. Methods: A total of four hundred and fiftysix $(\mathrm{N}=456)$ students were recruited through proportionate sampling. The Center for Epidemiologic Studies Depression Scale Revised (CESD-R) and Adult Suicidal Ideation Questionnaire (ASIQ) were used to measure depression and suicidal ideation, respectively. Results: The results show that there was a weak and positive relationship between depression and suicidal ideation among university students $(r=.22)$. A significant difference of depression was found between genders $(p<.05)$, on the contrary no significant difference on suicidal ideation between genders ( $p>05$ ) Conclusion: This study helps in examining the relationship and difference in depression and suicidal ideation among university students. Female has higher depression than male counterpart due to poor control over emotion. In conclusion, as depression increases, the suicidal ideation also increases among university students.
\end{abstract}

Keywords: Depression, Suicidal Ideation, Male, Female, University Students.

\section{Introduction}

In Malaysia, depression is the most common mental health illness with increasing rate and increasing from 10.7 \% in 1996 to $11.2 \%$ in 2006, and $29.2 \%$ in 2015 (New Straits Times, 2018). Previous review reported that the prevalence of depression among university students was higher than the general population (Ibrahim et al., 2013). Suleiman et al (2017) found that university students, especially first-year students have depression due to various psychosocial changes where they need to adapt to new environment such as academic and social demand, prepare future expectation and deal with homesickness. Besides, university students are also depressed for obtaining higher CGPA and getting the highest score in the examination (Baharudin, 2016).

Depression is a very crucial public health concern that often associated with depressed mood, loss of concentration or desire, decreased energy, feelings of guilt or low self-esteem, troubled in sleeping or hunger, and poor focus in doing something doing something (WHO, 
2012). Depression affects mental health problems between the young group mostly institution of higher learning students due to stress caused from studies and independent living (Islam et al., 2018). Zuo et al (2020) proposed that stressful life events have a direct and positive influence on depression. Depression usually linked with a decrease in the quality of life, increased morbidity and mortality. Furthermore, depressions also influence physical and psychological well-being as it is related to acute contagious diseases, suicidal thoughts, and suicide (Buchanan, 2012; Zuo et al., 2020).

In Malaysia, the prevalence of major depressive disorder was reported about $5.6 \%$ and it was shown to be a powerful trigger of suicide, among college students (Suleiman et al., 2017). Wasserman and Wasserman (2010) defined suicidal ideation as thinking about and engaging in it, writing, talking or planning it. Johal and Sharma (2016) proposed that suicidal ideation refers to a scale of thoughts ranging from mild to severe about death, which include thoughts and feelings about death, hurting them self, or even to the "planning, conduct and result" of own suicide. Suicidal ideation alone may lead to serious suicidal behaviours.

According to Menezes et al (2012), 10.7\% and 18.4\% of 206 undergraduate had suicidal ideation while only $1.0 \%$ of respondents had a suicide plan or a suicide attempt due to dissatisfaction with academic performance, being in the clinical semesters, having history of drug abuse and feeling neglected by parents. Depression was the second strongest predictor for suicide in the past study by Tin et al (2014). Shamsuddin, Fadzil, Ismail, Shah, Omar and Muhammad (2013) reported the level of depression among Malaysian university students at moderate, severe and extremely severe depression were $27.5 \%, 9.7 \%$ and 9.7 respectively. This was due to various factor that may contribute to depression which includes (and not limited to) poor academic performance, life satisfaction, social support, life stressor, physical inactivity, overweight or obesity, and sleeping problems.

Past studies focused on gender differences in depression and revealed that females have higher depression compared to male. Armstrong and Oomen-Early (2009) found that female college students had higher depression than male students. Islam et al (2016) stated that female students more depressed than male students due to academic stress and future careers. However, Kok and Goh (2011) view of point said that suicidal ideation is higher in males as compared to females due to love relationships. There was also another study stated that there was no difference in depression between both genders where it shows a low level of depression among university students (Sarokhani et al., 2013; Mustaffa et al., 2013). Ram et al (2018) also stated that suicidal ideation was more prevalence among females as compared to male students. Study by Osama et al (2014) supports this statement where females' students have a higher prevalence of suicidal ideation than males' students. However, Panda (2015) found that there were no significant differences between male and female students on suicidal ideation.

Thus, this study aimed to measure the relationship and difference between depression and suicidal ideation among undergraduate university students in Sarawak, Malaysia. Besides, to the extent of researchers' knowledge, to this current date there was lack of study done on determining the relationship of depression and suicidal ideation among universities students specifically in Sarawak. Therefore, the research objectives of this study were;

- To examine the difference of depression between male and female university students. 
- To examine the difference of suicidal ideation between male and female university students.

- To examine the relationship between depression and suicidal ideation among university students

\section{Methodology \\ Research Design}

The present study utilized a quantitative method using cross-sectional study. The present study was aimed to measure depression and suicidal ideation.

\section{Sampling}

The present study was carried out among undergraduate university students $(N=19,840)$ of UiTM Sarawak ( $n=7621)$ and UNIMAS $(n=12,219)$. Based on Krejcie and Morgan (1970) formula, $n=377$ respondents were required for the study. A total of $456(n=456)$ questionnaires were distributed comprising - twenty percent (20\%) dropout rate. A proportionate sampling technique was used in deriving the sample size from each university; UiTM Sarawak ( $n=175)$; UNIMAS $(n=281)$.

\section{Instrumentations}

The data were collected by using self-administered questionnaires. The Center for Epidemiologic Studies Depression Scale-Revised (CESD-R) by Radloff (1977) was used to measure depression. CESD-R ( $r=0.85$ ) were using a 4-point Likert scale which scale 1 defined as rarely or none of the time (less than 1 day). For scale 2, the rate defined as some or a little of the time (1-2 days) whereas. scale 3 defined as occasionally or a moderate amount of time (3-4 days). Lastly, scale 4 defined as most or all the time (5-7 days). Meanwhile, the Adult Suicidal Ideation Questionnaire (ASIQ) by Reynolds (1991) was used to measure suicidal ideation. ASIQ ( $r=0.97)$ were using a 6 -point likert scale which indicated $(0=1$ never had this thought; 1 = I has this thought before but not in the past month; 2 = About once a month; 3 = Couple of times a month; $4=$ About once a week; $5=$ Couple of times a week; $6=$ Almost every day).

\section{Procedure}

The respondents were informed that the participation is voluntarily and assured that the information is confidential and only used for research purposes. The respondents answered the questionnaires which were consisted of demographics profile, CESD-R and ASIQ questionnaires approximately in 20-30 minutes, and researchers collected all the questionnaires upon the completion.

\section{Data Analysis}

The purpose of this study was to investigate difference of depression and suicidal ideation and the relationship between depression and suicidal ideation among university students. The data collected was analysed by using the Statistical Package for Social Sciences (SPSS Version 22.0). Both descriptive and inferential statistics were carried out in answering the research objectives of this study. Descriptive data was presented in mean $(M)$ and standard deviation $(S D)$, frequencies and percentages. Independent Sample T-test was used to identify the difference of depression and suicidal ideation between gender. The significant 
difference was set at $<.05$. While, Pearson Correlation Coefficient was used to identify the relationship between depression and suicidal ideation among undergraduate students.

\section{Results and Findings}

\section{Descriptive Statistics}

Table 1 showed the demographic information of respondents in the present study. There were $456(n=456)$ undergraduate students were involved in this study. The respondents were divided proportionately according to the number of students based on the universities involved comprised of UiTM Sarawak $(n=175)$ and UNIMAS $(n=281)$; with $50 \%$ male $(n=228)$ and $50 \%$ female $(n=228)$ students.

Table 1: Characteristics of the Participants

\begin{tabular}{ccc}
\hline Gender & $\boldsymbol{n}$ & $\mathbf{( \% )}$ \\
Male & 228 & \\
Female & 228 & 50.0 \\
& & 50.0 \\
Age of Respondents & & \\
$18-21$ & 291 & 63.8 \\
$22-25$ & 157 & 34.4 \\
26 and above & 8 & 1.8 \\
\hline
\end{tabular}

Table 2: Total Number of Respondents Based on Universities

\begin{tabular}{ccc}
\hline & $\boldsymbol{n}$ & $\mathbf{( \% )}$ \\
\hline UiTM & 175 & 38.4 \\
UNIMAS & 281 & 61.6 \\
\hline Total & 456 & 100.0 \\
\hline
\end{tabular}

Table 3 showed the depression scores of the respondents. Meanwhile, Table 4 displayed the mean $(M)$ and standard deviation $(S D)$ of depression and suicidal ideation among university students.

Table 3: Scoring for Depression

\begin{tabular}{ccc}
\hline Depression Level & $\boldsymbol{n}$ & (\%) \\
\hline $0-16$ (No to Mild Depression) & 353 & $77.4 \%$ \\
$16-23$ (Moderate depression & 74 & $16.2 \%$ \\
$24-60$ (Severe depression) & 29 & $6.4 \%$ \\
\hline Total & 456 & 100.0 \\
\hline
\end{tabular}

Table 4: Mean and Standard Deviation for Depression and Suicidal Ideation

\begin{tabular}{lcc}
\hline Variables & $\boldsymbol{M}$ & SD \\
\hline Depression & 1.46 & 0.54 \\
Suicidal Ideation & 0.73 & 1.09 \\
\hline
\end{tabular}




\section{Depression and Suicidal Ideation between Genders}

An independent sample T-Test was used to examine the difference of depression and suicidal ideation as measured by CESD-R and ASIQ scores. Table 5 result highlight that there was a significant difference $(p=.01)$ in depression between male $(M=1.39, S D=.51)$ and female $(M=1.52, S D=.57)$. Table 6 whereas showed that there was no significant difference $(p=.96)$ in suicidal ideation between male $(M=.73, S D=1.09)$ and female $(M=.74, S D=1.10)$ university students.

Table 5: Depression between Genders

\begin{tabular}{ccccc}
\hline Gender & $\boldsymbol{n}$ & $\boldsymbol{M}$ & SD & Sig. \\
\hline Male & 228 & 1.39 & .51 & .01 \\
Female & 228 & 1.52 & .57 & \\
\hline
\end{tabular}

Table 6: Suicidal Ideation between Genders

\begin{tabular}{lllll}
\hline Gender & $\boldsymbol{n}$ & $\boldsymbol{M}$ & SD & Sig. \\
\hline Male & 228 & .73 & 1.09 & .96 \\
Female & 228 & .74 & 1.10 & \\
\hline
\end{tabular}

\section{Relationship between Depression and Suicidal Ideation}

The relationship between depression and suicidal ideation was identified by using the Pearson Correlation Test. Pallant (2013) specified that the weak relationship is ranged from $r$ $=.10$ to $r=.29$; medium relationship is ranged from $r=.30$ to $r=.49$; while the strong relationship is ranged from $r=.50$ to $r=1.0$. In general, there was a weak relationship between depression and suicidal ideation as reflected in Table 7 . There was a significant positive correlation between depression and suicidal ideation among university students with value $r$ $=.22, n=456, p=<.05$.

Table 7: Relationship between Depression and Suicidal Ideation

\begin{tabular}{lc}
\hline & Depression \\
\hline Suicidal Ideation & .22 \\
\hline
\end{tabular}

\section{Discussion}

The aims of present study were to investigate the differences between depression and suicidal ideation between male and female, and to identify relationship between depression and suicidal ideation among university students. The present study found that there was a significant difference in depression between male and female university students. Female students have a higher mean score of depression as compared to male students. From the result, it is clearly that consistent with the past study by Ghaedi and Kosnin (2014) which stated that the level of depression presents more frequently among females compared to males due to the greater degree of stress. Stress led to increase hormones such as cortisol, which is known as the stress hormone and reduced serotonin and dopamine that linked with depression (Cowen, 2002). The possible reason for current finding was due to female students unable to control their emotion that lead to depression. This reason was supported by Khalil, Rabie, and Abdou (2010) which indicated that pessimism, sadness, and low self-esteem can lead to depression. This may explain that low self-esteem, lack of social support and negative thinking and experiences in female recognized as a predictor for depression (Wainwright \& 
Surtees, 2002). The result suggested that female prone to become more sensitive due to lack of monoamines in the brain such as serotonin and dopamine that cause depression. This monoamine is beneficial for depressed people because such chemicals in the brain directly affect someone's mood (Salehian et al., 2012).

The current study found that there was no difference of suicidal ideation between male and female university students. This finding is parallel with the past study by Eskin et al (2011) and Panda (2015). The possible reason for this finding was because of university students were faithful to their respective religions. According to Engin et al (2009), suicide considered a sin according to the Islamic religion. In addition, the Suicide Prevention Resource Center (2009) reported that suicide is an act against God and considered a sin according to the Christian. Another past study by Mahmound et al (2012) indicated that students who identified with a religion showed signs of less depression. Besides, Cook (2014) also stated that suicidal ideation is lower among those who are religious. There are many programs like campaign and motivation to talk about mental health. With proper mental health awareness campaign, it can promote the positive outcome that can enhance the mental health literacy which it increases the awareness and knowledge of the mental health disorders (Brown et al., 2010). Befrienders Kuching organized health carnival aimed to promote mental health awareness and suicide prevention. Befrienders Penang also organized two events under Suicide Prevention Campaign with Mental Health alliance Penang where there is a workshop in Mandarin on mindfulness to promote better mental health and prevent suicide and Seminar for Awareness Raising on Suicide Prevention (Befrienders Worldwide, 2014).

Another promising finding, the study found that there was a weak, significant positive correlation between depression and suicidal ideation among university students. The current findings are consistent with few past studies (Singh \& Joshi, 2008; Herrera et al., 2013; Mustaffa et al., 2014). Extensive results carried out show that, when the level of depression increases thus the suicidal ideation also increase. Depression is one of the causes that lead to suicidal ideation. This reason supported by Singh and Joshi (2008) which stated that depression consider as a potential risk factor for suicidal ideation or suicide itself. Past researcher had summarised factor such as confusion, sexual abuse, work, and trauma lead to depression which this contributes to the risk of suicide (Reeves, 2010). Besides, Schwartz and Cohen (2001) found that depression is the most significant factor in predicting suicidal actions. Pervin and Ferdowshi (2016) indicated that students that had unpredictable depression are at greater risk for suicide and tend to have a lack of ability to overcome suicide ideas and may plan to commit suicide. Depression affecting individual daily performance and social relationships increase the emergence of these thoughts and even attempting suicide (Levine, 2008).

\section{Conclusions}

In conclusions, the present study showed a weak positive relationship between depression and suicidal ideation among the undergraduate university students. In addition, there was significant difference on depression between gender but no significant difference on suicidal ideation between gender. Therefore, more studies are required to examine the relationship and difference between depression and suicidal ideation. In addition, these findings can provide information and reference for the future researcher to conduct research related to guidelines on depression and suicidal ideation among undergraduate university students. 


\section{Contributions}

The present research suggests a weak positive relationship between depression and suicidal ideation. University students who have experienced an episode of depression, they are having thoughts of suicide. Depression is a mood disorder that can lead to suicidal ideation. These findings help the institutions to be more aware of depression and suicidal ideation which the institution can organize programs related to mental health such as motivational talk or any campaign.

\section{Acknowledgement}

We would like to acknowledge University Technology MARA (UiTM) Sarawak Branch because giving us the opportunity to complete this research successfully.

\section{References}

Armstrong, S., \& Oomen-Early, J. (2009). Social connectedness, self-esteem, and depression symptomatology among collegiate athletes versus nonathletes. Journal of American College Health, 521-526.

Baharudin, H. (2016). Depression among College Student: Case Study in UiTM Puncak Perdana. Research Hub.

Befrienders Worldwide (2014). World Suicide Prevention Day.

Brown, V. A., Harris, J. A., \& Russell, J. Y. (2010). Tackling wicked problems through the transdisciplinary imagination.

Buchanan, J. (2012). Prevention of depression in the college student population: a review of the literature. Archives of Phychiatric Nursing, 21-42.

Cook, C. (2014). Suicide and religion. British Journal of Psychiatry, 204(4), 254-255. doi:10.1192/bjp.bp.113.136069.

Cowen, P. (2002). Cortisol, serotonin and depression: all stressed out? The British Journal of Psychiatry, 99-100.

Engin, E., Gurkan, A., Dulgerler, S., \& Arabaci, L. B. (2009). University students' suicidal thoughts and influencing factors. Journal of Psychiatric and Mental Health Nursing, 343-354.

Eskin, M., Voracek, M., Stieger, S., \& Altinyazar, V. (2011). A cross-cultural investigation of suicidal behavior and attitudes in Austrian and Turkish medical students. Social Psychiatry and Psychiatric Epidemiology, 813- 823.

Ghaedi, L., \& Kosnin, A. (2014). Prevalence of Depression among Undergraduate Students: Gender and Age Differences. Int. J. Psychol.Res, 38-50.

Herrero, A., Sabado, T., \& Benito, G. (2014). Associations between emotional intelligence, depression and suicide risk in nursing students. Nurse Education Today, 520-525.

Ibrahim, A. K., Kelly, S. J., Adams, C. E., \& Glazebrook, C. (2013). A systematic review of studies of depression prevalence in university students. Journal of psychiatric research, (3), 391400.

Islam, M. A., Low, W. Y., Tong, W. T., Yuen, C. C., \& Abdullah, A. (2018). Factors Associated with Depression among University Students in Malaysia: A Cross-sectional Study. KnE Life Sciences, (4), 415.

Johal, D. S., \& Sharma, M. (2016). Suicide Ideation and Life Satisfaction among Adolescents: A Correlational Study. Journal of Humanities and Social Science, 23-28. 
Khalil, A. H., Rabie, M. A., Abd-El-Aziz, M. F., Abdou, T. A., El-Rasheed, A. H., \& Sabry, W. M. (2010). Clinical characteristics of depression among adolescent female: A crosssectional study. Child and Adolescent Psychiatry and Mental Health.

Kok, J. K., \& Goh, L. Y. (2011). Young People and Suicide Issue. International Conference on Humanities, Society and Culture.

Levine, H. (2008). Suicide and its impact on campus. New directions for student services, 2008(121), 63-76.

Mahmoud, J., Staten, R., Hall, L. A., \& Lennie, T. (2012). The relationship among young adult college students' depression, anxiety, stress, demographics, life satisfaction, and coping styles. Issues in Mental Health Nursing, 149-156.

Menezes, R. G., Shubba, S., Sathian, B., Kharoshah, M., Senthilkumaran, S., Pant, S., Shankar, P. R. (2012). Suicidal ideation among students of a medical college in Western Nepal: A cross-sectional study. Legal medicine, 183-187.

Mustaffa, S., Aziz, R., Mahmood, M., \& Shuib., S. (2014). Depression and Suicidal Ideation Among University Students. Procedia - Social and Behavioral Sciences, 4205-4208.

News, T. S. (2018). Depression On the Rise.

Osama, M., Islam, M. Y., Hussain, S. A., Masroor, S. Z., Burney, M., Masood, M., Rehman, R. (2014). Suicidal ideation among medical students of Pakistan: A crosssectional study. Journal of Forensic and Legal Medicine, 65-68.

Panda, S. (2015). The Association between Depression and Suicidal Ideation among Postgraduate University Students. The International Journal of Indian Psychology

Pallant, J. (2013). SPSS survival manual. McGraw-Hill Education (UK).

Pervin, M. M., \& Ferdowshi, N. (2016). Suicidal Ideation In Relation To Depression, Loneliness and Hopelessness Among University Students. Dhaka Univ. J. Biol. Sci, 57-64.

Radloff, L. S. (1977). The CES-D scale: A self-report depression scale for research in the general population. Applied Psychological Measurement, 383-401.

Reeves, A. (2010). Counselling suicidal clients. Sage.

Reynolds, W. M. (1991). Psychometric characteristics of the Adult Suicidal Ideation Questionnaire in college students. Journal of personality assessment, 56(2), 289-307.

Salehian, M. H., Gursoy, R., Aftabi, G. R., Sardarudi, M. T., \& Anvari, Z. D. (2012). Comparison of depression between university athletes and non-athletes. European Journal of Experimental Biology, 1008-1011.

Sarokhani, D., Delpisheh, A., Veisani, Y., Sarokhani, M. T., Manesh, R. E., \& Sayehmiri, K. (2013). Prevalence of Depression among University Students: A systematic Review and Meta-Analysis Study. Depression Research and Treatment.

Singh, R., \& Joshi, H. L. (2008). Suicidal Ideation in Relation to Depression, Life Stress and Personality among College Students. Journal of Indian Academy of Applied Psychology, 259-265.

Suicide Prevention Resource Center. (2009). The role of faith communities in preventing suicide: A report of an Interfaith Suicide Prevention Dialogue. Newton, MA: Education Development Center, Inc.

Suleiman, A. K., Ismadi, N. I., Choundhry, F. R., Munawar, K., \& Hameed, M. A. (2017). Determinant Factors of Depression: A survey Among University Students. Malaysian Journal of Public Health Medicine, 97-103.

Schwartz, R. C., \& Cohen, B. N. (2001). Risk factor for suicidality among clients with schizophrenia. Journal of Counselling and Development, 314-319. 
Tin, T. S., Sidik, S. M., Rampal, L., \& Ibrahim, N. (2014). Prevalence and Predictors of Suicidality Among Medical Students in A Public University.

Wasserman, D., \& Wasserman, C. (2010). The Oxford Textbook of Suicidology and Suicide Prevention: A Global Perspective. International Academy for Suicide Research, 109-110.

Wainwright, N. W. J., \& Surtees, P. G. (2002). Childhood adversity, gender and depression over the life-course. Journal of Affective Disorders, 33-44.

WHO. (2012). Depression: A Global Crisis. Geneva, World Health Organization.

Zuo, B., Zhang, X., Wen, F., \& Zhao, Y. (2020). The influence of stressful life events on depression among Chinese university students: Multiple mediating roles of fatalism and core self-evaluations. Journal of Affective Disorders, 260, 84-90. doi:10.1016/j.jad.2019.08.083. 